\title{
Hypoxic Induction of Interleukin-8 Gene Expression in Human Endothelial Cells
}

\author{
M. Karakurum, * R. Shreeniwas," J. Chen, " D. Pinsky, " S-D. Yan, * M. Anderson," K. Sunouchi," \\ J. Major," T. Hamilton, ' K. Kuwabara, * A. Rot, " R. Nowygrod, ${ }^{*}$ and D. Stern* \\ Departments of ${ }^{*}$ Physiology and ${ }^{\ddagger}$ Surgery, Columbia University, College of Physicians and Surgeons, New York, 10032; ${ }^{\circledR}$ Cleveland \\ Clinic Foundation Research Institute, Cleveland Ohio 44195; "Merck, Sharp and Dohme, West Point, Pennsylvania 19486; and 'Vienna \\ International Research Cooperation Center at Sandoz Forschungsinstitut, A 1235, Vienna, Austria
}

\begin{abstract}
Because leukocyte-mediated tissue damage is an important component of the pathologic picture in ischemia/reperfusion, we have sought mechanisms by which PMNs are directed into hypoxic tissue. Incubation of human endothelial cells (ECs) in hypoxia, $\mathrm{PO}_{2} \sim$ 14-18 Torr, led to time-dependent release of IL-8 antigen into the conditioned medium; this was accompanied by increased chemotactic activity for PMNs, blocked by antibody to IL-8. Production of IL-8 by hypoxic ECs occurred concomitantly with both increased levels of IL-8 mRNA, based on polymerase chain reaction analysis, and increased IL-8 transcription, based on nuclear run-on assays. Northern analysis of mRNA from hypoxic ECs also demonstrated increased levels of mRNA for macrophage chemotactic protein-1, another member of the chemokine superfamily of proinflammatory cytokines. IL-8 gene induction was associated with the presence of increased binding activity in nuclear extracts from hypoxic ECs for the NF-kB site. Studies with human umbilical vein segments exposed to hypoxia also demonstrated increased elaboration of IL-8 antigen compared with normoxic controls. In mice exposed to hypoxia ( $\mathrm{PO}_{2} \sim 30-40$ Torr), there was increased pulmonary leukostasis, as evidenced by increased myeloperoxidase activity in tissue homogenates. In parallel, increased levels of transcripts for IP-10, a murine homologue in the chemokine family related to IL-8, were observed in hypoxic lung tissue. Taken together, these data suggest that hypoxia constitutes a stimulus for leukocyte chemotaxis and tissue leukostasis. (J. Clin. Invest. 1994. 93:1564-1570.) Key words: hypoxia $\bullet$ leukostasis $\bullet$ ischemia $\bullet$ cytokine $\bullet$ chemokine
\end{abstract}

\section{Introduction}

There is a large pool of resident macrophages in the lung; neutrophils (PMNs), as well as additional mononuclear phagocytes are recruited in response to inflammatory stimuli (1-2). Lung vasculature is also sensitive to hypoxia, as indicated by the rapid vasoconstriction which occurs with decreased oxygen tension in the alveoli (3). Since vascular injury and hypoxia can involve PMNs (4-10), we have focussed on mechanisms which selectively draw leukocytes into ischemic loci. In this context, two important mechanisms are enhanced expression

Address correspondence to Dr. David Stern, Department of Physiology, Columbia University, College of Physicians and Surgeons, 630 West 168th Street, New York, NY 10032.

Received for publication 15 December 1992 and in revised form 5 November 1993.

J. Clin. Invest.

(c) The American Society for Clinical Investigation, Inc.

0021-9738/94/04/1564/07 \$2.00

Volume 93, April 1994, 1564-1570 of leukocyte adhesion molecules on the endothelial cell (EC) ${ }^{1}$ surface, and the generation of chemoattractant cytokines leading to egress of PMNs from the intravascular space. Enhanced PMN-vascular interactions have also been demonstrated in ischemic tissues in association with increased generation of reactive oxygen intermediates (11-14), increased expression of platelet-activating factor (15-17), as well as the increased expression of IL-1, which occurs during hypoxemia $(\mathrm{H})$ and reoxygenation $(R)(18-19)$. These observations have led us to seek mechanisms through which PMNs would leave the intravascular space in hypoxic tissues.

The studies reported here demonstrate that exposure of ECs to hypoxia leads to early, de novo synthesis of IL-8: transcription is enhanced, levels of steady state mRNA rise, and increased amounts of chemotactically active protein are elaborated. Increased IL-8 production is also observed in human umbilical cord segments exposed to hypoxia, compared with normoxic controls. Further, in a mouse model of hypoxia, a gene in the IL-8 chemokine superfamily of proinflammatory cytokines, IP-10 (20-22), is induced and there is increased myeloperoxidase activity in the lung, consistent with PMN infiltration. One mechanism underlying hypoxia-mediated induction of IL-8 may be early activation of a transcription factor recognizing a nuclear factor $\mathrm{kB}$ (NF-kB) site. The importance of understanding the expression of IL-8 in response to hypoxia is emphasized by a recent study demonstrating induction of IL-8 in mononuclear phagocytes exposed to anoxia followed by reoxygenation (23). To further complete the profile of IL-8 expression in $\mathrm{H} / \mathrm{R}$, our studies show that ECs, the first cells of the vessel wall which encounter PMNs, produce IL-8 during hypoxia even before the mononuclear phagocyte response during $R$ resulting in IL-8 elaboration. Taken together, these data contribute to an emerging picture of ischemia-driven mechanisms underlying the inflammatory response.

\section{Methods}

Endothelial cell culture and exposure of cells and umbilical cord segments to $H / R$. Human umbilical vein ECs were prepared from umbilical cords and grown in culture by the method of Jaffe (24) as modified by Thornton (25). Experiments used confluent ECs (passages 1-4) grown in Medium 199 supplemented with fetal bovine serum (15\%; Gemini, Calabasas, CA), human serum (5\%; Gemini), endothelial growth supplement (Sigma Immunochemicals, St. Louis, MO), heparin ( $90 \mu \mathrm{g} / \mathrm{ml}$; Sigma Immunochemicals) and antibiotics, as described (18). When ECs achieved confluence, experiments were performed by placing cultures in an environmental chamber (Coy Laboratory Prod-

1. Abbreviations used in this paper: EC, endothelial cells; GAPDH, glyceraldehyde phosphate dehydrogenase; $H / R$, hypoxia/reoxygenation; IP-10, a murine homologue in the chemokine family related to IL-8; MCP-1, macrophage chemotactic protein-1; MPO, myeloperoxidase; NF-kB, nuclear factor $\mathrm{kB}$. 
ucts, Inc., Ann Arbor, MI), which provided a controlled temperature $\left(37^{\circ} \mathrm{C}\right)$ and atmosphere with the indicated amount of oxygen, carbon dioxide (5\%), and the balance made up of nitrogen. Use of this chamber for cell culture experiments has been described previously (26). During exposure of ECs to hypoxia (for a maximum of $16 \mathrm{~h}$ ), the oxygen tension in the culture medium was 14-18 Torr and there was no change in the medium $\mathrm{pH}$. Reoxygenation was performed by placing ECs in an ambient atmosphere containing carbon dioxide (5\%) at $37^{\circ} \mathrm{C}$. Cell viability was monitored by trypan blue exclusion and determination of lactate dehydrogenase release into the medium, as measured with a kit purchased from Sigma Immunochemicals.

For certain experiments umbilical cords were obtained immediately after delivery, washed in balanced salt solution, trimmed to remove excess adventitial tissue, and each cord was cut into pieces such as to expose the umbilical vein endothelial cell surface. The pieces/vessel segments were immersed in Medium 199 containing fetal bovine and human serum (1\%), and were incubated in the hypoxia chamber (as above) or in a normoxic incubator (usual atmospheric culture conditions with 5\% carbon dioxide) for $6 \mathrm{~h}$. For each of three cords, IL-8 was determined by triplicate measurements comparing segments exposed to normoxia vs those segments exposed to hypoxia. Aliquots of culture medium were assayed for IL-8 antigen in the ELISA described below.

Assays for expression of IL-8 and Northern analysis for macrophage chemotactic protein-1 (MCP-1). IL-8 antigen was quantified using a sensitive capture ELISA (27). Mouse monoclonal anti-neutrophil activating protein-1/IL-8 IgG (Sandoz Forschungsinstitut, Vienna, Austria) was used to coat wells of microtiter plates for $16 \mathrm{~h}$ at $4^{\circ} \mathrm{C}$. After washing four times with phosphate-buffered saline (Gibco Laboratories, Grand Island, NY) containing Tween $20(0.05 \%)$, purified human recombinant IL-8 (Sandoz, Basel, Switzerland) at concentrations of $0.02-10 \mathrm{ng} / \mathrm{ml}$ or conditioned media from EC cultures was added to the precoated wells for $2 \mathrm{~h}$ at $37^{\circ} \mathrm{C}$. Plates were rinsed four times with phosphate-buffered saline containing Tween-20, as above, and goat anti-IL-8 IgG conjugated to alkaline phosphatase was added for an additional $2 \mathrm{~h}$ at $37^{\circ} \mathrm{C}$. Next, substrate, $p$-nitrophenyl phosphate was added, and plates were further incubated to allow color development, followed by termination of the reaction with $\mathrm{NaOH}(2 \mathrm{~N})$. Absorbance was read at $405 \mathrm{~nm}$, and the detection limit in this assay was $3.0 \mathrm{pg} / \mathrm{ml}$. The experiment was repeated on five separate occasions, and the results are expressed as fold increase in IL-8 production over normoxic controls.

Assays for PMN chemotaxis were performed in modified chemotaxis chambers as described previously (28-29). In brief, to harvest PMNs, blood from healthy donors was drawn into EDTA (final concentration, $5 \mathrm{mM}$ ), and diluted $1: 1$ with $\mathrm{NaCl}(0.9 \%)$ followed by gradient ultracentrifugation on Ficoll Hypaque (Pharmacia Fine Chemicals, Piscataway, NJ). Leukocyte chemotaxis was performed in 48-well chemotaxis chambers (Neuro Probe, Bethesda, MD) containing a 5- $\mu \mathrm{m}$ nucleopore polycarbonate membrane (Nucleopore Corp., Pleasanton, CA). PMNs were suspended in serum-free Medium 199 (Gibco Laboratories) and $10^{4}$ cells were added per well to the upper chamber. The lower chamber contained either conditioned medium from hypoxic ECs, purified IL-8, or medium alone. The chamber was incubated for $30 \mathrm{~min}$ at $37^{\circ} \mathrm{C}$ in a humidified air atmosphere containing carbon dioxide ( $5 \%$ ), and after $30 \mathrm{~min}$, the membrane was washed, fixed in methanol, and Wright stained. Nine high power fields were counted per sample, and each experiment was done in triplicate. The results are expressed as the mean of three experiments.

PCR analysis of IL-8 transcripts was assessed in cultured ECs exposed to normoxia, hypoxia, or $H / R$, and total RNA was extracted using the acid-guanidinium thiocyanate procedure (Stratagene, La Jolla, CA). Random hexanucleotide-primed first-strand cDNA was prepared and served as a template for PCR analysis. IL-8 primers were those described by Carre et al. (30) and glyceraldehyde phosphate dehydrogenase (GAPDH) primers ( 19) were 5' CCA CCC ATG GCA AAT TCC ATG GCA 3' (sense) and 5' TCT AGA CGG CAG GTC AGG TCC ACC 3' (antisense). cDNA was amplified by PCR for 30 cycles, each cycle consisting of incubations at $94^{\circ} \mathrm{C}$ for $1 \mathrm{~min}, 50^{\circ} \mathrm{C}$ for $2 \mathrm{~min}$, and $72^{\circ} \mathrm{C}$ for $2 \mathrm{~min}$. Products were analyzed by $1 \%$ agarose gel electrophoresis and visualized by ethidium bromide staining under ultraviolet light, transferred to nylon membranes, and Southern hybridization was performed using ${ }^{32} \mathrm{P}$-labeled cDNA encoding full-length human IL-8. In control studies, the same cDNA was amplified with human GAPDH primers described above.

Detection of a murine homologue in the chemokine family related to IL-8 (IP-10) and KC mRNA was also done using PCR amplification of cDNA generated by reverse transcription using RNA from lung tissue of mice exposed to hypoxia (see below) as the sample. $5 \mu \mathrm{g}$ of each RNA was used as starting material for the reverse transcription reaction in a total volume of $18 \mu \mathrm{l}$, and $9 \mu \mathrm{l}$ of the latter reaction product was then amplified by PCR. Primers used for IP- 10 were sense ( $5^{\prime}$ AAC CCA AGT GCT GCC $3^{\prime}$ ) and antisense ( $5^{\prime}$ ACC ATG GCT TGA CCA $3^{\prime}$ ), and for KC were sense ( $5^{\prime}$ TCG CTT CTC TGT GCA GCG CT 3') and antisense ( $5^{\prime}$ GTG GTT GAC ACT TAG TGG TCT C 3') (2022). Amplification was carried out for 35 cycles with an annealing temperature of $60^{\circ} \mathrm{C}$. After amplification, $20 \mu \mathrm{l}$ of reaction product was separated by agarose gel ( $1 \%)$ electrophoresis, stained with ethidium bromide, and blotted onto nylon membranes for Southern hybridization. The blots were hybridized with a radiolabeled cDNA probe for IP-10 using standard methodologies.

Northern analysis for MCP-1 was performed on total cellular RNA extracted by the acid guanidinium thiocyanate method, as above. Equal amounts of RNA ( $8 \mu \mathrm{g}$ ) were denatured and subjected to electrophoresis in a $1 \%$ agarose formaldehyde gel as previously described (30). The RNA was then blotted by capillary transfer to nylon membranes. The blots were prehybridized for $6-8 \mathrm{~h}$ at $42^{\circ} \mathrm{C}$ in formamide $(50 \%)$, SDS ( $1 \%)$, SSC ( $5 \times)$, Denhardt's solution ( $1 \times$; Ficoll, $0.02 \%$; bovine serum albumin, $0.02 \%$; polyvinylpyrrolidone, $0.02 \%$ ), denatured herring testes DNA $(0.25 \mathrm{mg} / \mathrm{ml})$, and sodium phosphate buffer ( $\mathrm{pH} 6.5 ; 50 \mathrm{mM}$ ). Hybridization was carried out at $42^{\circ} \mathrm{C}$ for $12-18 \mathrm{~h}$ with MCP-1 probe obtained from American Type Culture Collection (Rockville, MD) ( $10^{7} \mathrm{cpm}$ in each case). Filters were washed (SDS, $0.01 \%$; SSC, $0.5 \times$ ) for $15 \mathrm{~min}$ at room temperature followed by a wash (SDS, $0.1 \% ; \mathrm{SSC}, 0.5 \times$ ) at $65^{\circ} \mathrm{C}$. Blots were then exposed to film (XAR-5; Eastman Kodak Co., Rochester, NY) with intensifying screens (Cronex Lightening Plus; Du Pont Pharmaceuticals, Wilmington, DE) at $70^{\circ} \mathrm{C}$. Expression of GAPDH was used as an internal control for the quantity of total mRNA. In addition, the RNA per lane was assessed by ethidium bromide staining of the original agarose gel after capillary transfer.

Nuclear run-on assays for IL-8, GAPDH, and $\beta$-actin. Isolation of nuclei and in vitro transcription were performed basically as described $(31,32)$. Briefly, EC cultures exposed to normoxia or hypoxia for $3 \mathrm{~h}$ were washed twice with ice-cold phosphate-buffered saline, lysed in NP-40-containing buffer (Tris/ $\mathrm{HCl}, 10 \mathrm{mM}, \mathrm{pH} 7.4 ; \mathrm{NaCl}, 10 \mathrm{mM}$; $\mathrm{MgCl}_{2}, 3 \mathrm{mM}$; NP-40, 0.5\%), incubated on ice for $5 \mathrm{~min}$, and centrifuged at $500 \mathrm{~g}$ for $5 \mathrm{~min}$. Nuclei were washed in lysis buffer, resuspended in storage buffer $(0.2 \mathrm{ml}$; Tris/ $\mathrm{HCl}, 50 \mathrm{mM}, \mathrm{pH} 8.3$; glycerol, $40 \% ; \mathrm{MgCl}_{2}, 5 \mathrm{mM}$; EDTA, $0.1 \mathrm{mM}$ ), and kept at $-80^{\circ} \mathrm{C}$ before use. For in vitro transcription, the nuclei from normoxic or hypoxic ECs $\left(7.2 \times 10^{6}\right)$ were thawed and mixed with equal volume of reaction buffer (Tris/ $\mathrm{HCl}, 10 \mathrm{mM}, \mathrm{pH} 8.0 ; \mathrm{MgCl}_{2}, 5 \mathrm{mM} ; \mathrm{KCl}, 300 \mathrm{mM}$ ) containing $1 \mathrm{mM}$ each of ATP, CTP, and GTP, and $\left[\alpha-{ }^{32}\right.$ P]UTP (200 $\mu \mathrm{Ci}, 3,000 \mathrm{Ci} / \mathrm{mmol}$; Amersham Corp., Arlington Heights, IL). The reaction mixture was incubated at $30^{\circ} \mathrm{C}$ for $30 \mathrm{~min}$, and ${ }^{32} \mathrm{P}$-labeled RNA was then isolated and precipitated with ethanol. RNA was hybridized to linearized plasmid DNA (IL-8, GAPDH, and $\beta$-actin), and immobilized on nitrocellulose membranes for $36 \mathrm{~h}$ at $65^{\circ} \mathrm{C}$, as described (31). Filters were washed in $\operatorname{SSC}(2 \times)$ at $65^{\circ} \mathrm{C}$ three times for $30 \mathrm{~min}$ each, incubated at $37^{\circ} \mathrm{C}$ with ribonuclease $\mathrm{A}(10 \mu \mathrm{g} / \mathrm{ml})$, washed again, air dried, and exposed to Kodak x-ray film as above.

Nuclear extracts and electrophoretic gel mobility shift assays. Nuclear extracts were prepared from normoxic and hypoxic ECs, or from endothelial cultures exposed to purified recombinant human TNF ( 5 nM) (generously provided by Dr. P. Lomedico, Hoffmann-La Roche 
Inc., Nutley, $\mathrm{NJ}$ ) for $3 \mathrm{~h}$ by the method of Dignam and Roeder (33). These extracts were prepared in an environment with the same ambient oxygen tension as that in the experiment (extracts from hypoxic cultures were prepared under hypoxia). Complementary 30-bp oligonucleotides representing a portion of the human IL-8 gene promoter containing a putative NF-kB site (34-35) or mouse NF-kB binding site (36-37) were used: for IL-8, these included 5' CCC CAA ATC GTG GAA TTT CCT CTG AGA TAA 3' (NF-kB1) and 5' GGG TTA TGT CAG AGG AAA TTC CAC GAT TTG 3' (NF-kB2); for mouse NF$\mathrm{kB}$ these included 5' CCC CAG AGG GGA CTT TCC GAG AGG CTC 3' (NF-kB1) and 5' GGG GAG CCT CTC GGA AAG TCC CCT CTG 3' (NF-kB2). Oligonucleotides were annealed and 3' end-labeled with $\left[\alpha-{ }^{32} \mathrm{P}\right] \mathrm{dCTP}$ and dGTP with Klenow polymerase via standard procedures (38). Binding reactions were performed by preincubating $7.5 \mu \mathrm{g}$ of nuclear extract protein in Hepes $(20 \mathrm{mM} ; \mathrm{pH} 7.9), \mathrm{KCl}(60$ $\mathrm{mM}), \mathrm{MgCl}_{2}$ (1 mM), EDTA (0.1 M), glycerol (10\%), dithiothreitol $(0.5 \mathrm{mM})$, and poly ( $\mathrm{dI}-\mathrm{dC} ; 2 \mu \mathrm{g})$ on ice for $10 \mathrm{~min}$, followed by addition of the double stranded ${ }^{32} \mathrm{P}$-labeled oligonucleotide $(\sim 0.2 \mathrm{ng})$ and a second incubation at room temperature for $20 \mathrm{~min}$. Samples were loaded directly onto nondenaturing $6 \%$ polyacrylamide gels (29:1 acrylamide/bisacrylamide) prepared in Tris ( $45 \mathrm{mM})$-boric acid (45 $\mathrm{mM})$-EDTA $(0.1 \mathrm{M})(0.5 \times \mathrm{TBE})$. Electrophoresis was performed at room temperature for 3-4 $\mathrm{h}$ at a current of $15 \mathrm{~mA}$. Supershift experiments were performed as described above except that $1 \mu \mathrm{l}$ of antibody to the NF-kB binding protein p50 or p65 were added to the binding mixture in the absence of the labelled probe. This mixture was then incubated on ice for $\mathbf{4 5} \mathrm{min}$ before probe addition. Antisera specifically recognizing p50 (anti-SP1141 from the $N$ terminus of p105) (39) or p65 (anti-SP1226 from the $\mathrm{N}_{2}$ terminus of p65) (39) were generously provided by Dr. N. Rice (Frederick Cancer Research and Development Center, Frederick, MD). The gels were then dried and exposed to Kodak XRP film with intensifying screens. For competition studies, unlabeled probe for $\mathrm{Spl}$ (40) was also used: 5' GCT CCA GGC GGG GGC GGG GCC CGG GTT CGG 3' (Sp-1-1\#) and 5' CCG AAC CCG GGC CCC GCC CCC GCC TGG AGC 3' (Sp-1-2\#). Experiments with unlabeled oligonucleotides used a 100 -fold molar excess relative to the radiolabeled oligonucleotide.

Determination of leukostasis and expression of IP-10/KC in lungs of hypoxic mice. Mice were subjected to hypoxia as previously described (26) and reoxygenated using a controlled environmental chamber. Animals were placed in the chamber and allowed free access to food and water, the system parameters were adjusted to a final oxygen concentration of $8-10 \%$ oxygen with the balance of the gas mixture being made up of nitrogen. At the indicated times, mice were killed, and lung was tissue collected for RNA extraction using the acid guanidinium thiocyanate method as described above. PCR and Southern blotting were performed as described above using primers for IP-10 and $\mathrm{KC}$.

Pulmonary leukostasis was assessed by determining myeloperoxidase (MPO) activity using previously described methods (41-42). Mice (hypoxic, $n=3$; normoxic, $n=3$ ) were anesthetized, lungs were rinsed with saline to remove residual blood, and then lungs were excised from the chest cavity and homogenized in phosphate buffer ( 50 $\mathrm{mM}$; pH 6.0) containing hexadecyl trimethyl ammonium bromide $(0.5 \%)$ on ice. The homogenate was centrifuged at $40,000 \mathrm{~g}$ for $10 \mathrm{~min}$ at $4^{\circ} \mathrm{C}$, and the supernatant decanted. The pellet was freeze thawed and resuspended in the same buffer (hexadecyl trimethyl ammonium bromide). This extraction procedure was repeated three times, the extracts were pooled, and MPO activity assayed using the standard chromogenic spectrophotometric technique $(20,21)$. The test sample $(0.1 \mathrm{ml})$ was added to $2.9 \mathrm{ml}$ of phosphate buffer ( $50 \mathrm{mM}$; pH 6.0) containing $O$-dianisidine dihydrochloride (Sigma Immunochemicals) and hydrogen peroxide $(0.0005 \%)$, and change in absorbance at $460 \mathrm{~nm}$ was measured during 5 min (increase in OD was linear during this time interval). Results shown are the means of three observations \pm SEM.

Data analysis. IL-8 ELISA and chemotaxis data were evaluated using analysis of variance, with the Tukey procedure used to discriminate significant differences between group means. When two variables were compared, the Student's $t$ test was used for unpaired (myeloperoxidase data) or paired (umbilical cord segment data) variables. Data were considered statistically significant if $P<0.05$.

\section{Results}

Elaboration of IL-8 by ECs exposed to hypoxia. When ECs were placed in an hypoxic atmosphere $\left(\mathrm{PO}_{2} \sim 14-18\right.$ Torr $)$, IL-8 antigen was released into the culture medium in a timedependent manner; increasing over time to $\sim 1 \mathrm{ng} / \mathrm{ml}$ by $16 \mathrm{~h}$ (Fig. $1 A$ ). After reoxygenation, IL-8 antigen continued to be
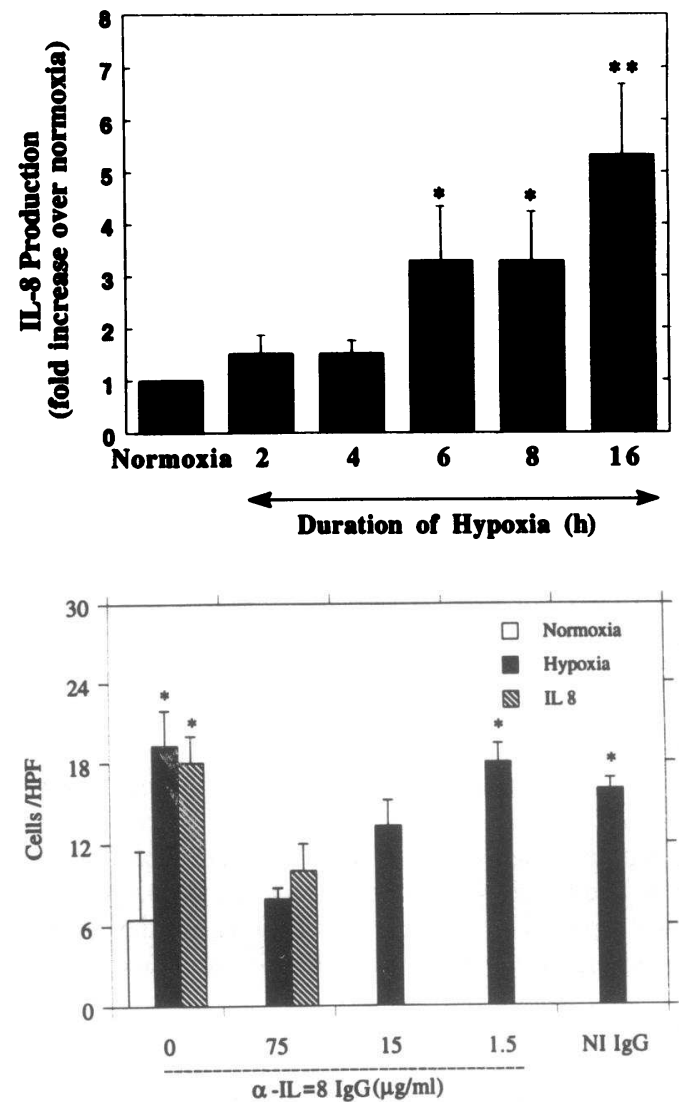

Figure 1. Hypoxia and H/R induce EC release of IL-8 antigen and PMN chemotactic activity into conditioned medium. $(A)$ Elaboration of IL-8 antigen. Confluent ECs were incubated in serum-free medium 199 in an hypoxic atmosphere (medium $\mathrm{PO}_{2} \sim 14-18$ Torr) for the indicated times. Aliquots of the culture supernatants were assayed for the presence of immunoreactive IL- 8 by ELISA. The $y$-axis indicates the rise in IL-8 antigen above that detectable in the conditioned medium of normoxic controls and is the mean of five separate experiments. The peak value of IL-8 antigen in hypoxic cultures was $\sim 1$ $\mathrm{ng} / \mathrm{ml}$ and was observed at $16 \mathrm{~h} .{ }^{*} P<0.05,{ }^{* *} P<0.01$. (B) Induction of PMN chemotaxis. Aliquots of conditioned medium from hypoxic EC cultures $(16 \mathrm{~h})$ were added alone (darkened bars) or in the presence of the indicated concentration of anti- $(\alpha)$-IL-8 IgG to the lower compartment of modified chemotaxis chambers. Where indicated, conditioned medium from normoxic ECs ( $16 \mathrm{~h}$; open bar) or purified IL-8 ( $1 \mathrm{ng} / \mathrm{ml}$; cross-hatched bar) was added to chemotaxis chambers. PMNs $\left(10^{4} /\right.$ well $)$ were placed in the upper chamber, and the assay was continued for $30 \mathrm{~min}$ at $37^{\circ} \mathrm{C}$ in a humidified ambient air atmosphere, as described in the text. $N I \operatorname{IgG}$, addition of nonimmune IgG at a final concentration of $75 \mu \mathrm{g} / \mathrm{ml}$. The $y$-axis shows the number of PMNs that migrated across the membranes in nine high powered fields. The mean \pm SEM of triplicate determinations is shown. ${ }^{*} P<0.05$. 
elaborated for up to $4 \mathrm{~h}$ (data not shown). Concomitantly, chemotactic activity for PMNs was observed in the conditioned medium from hypoxic EC cultures, which could be completely blocked in the presence of monospecific anti-IL-8 antibody, whereas nonimmune IgG was without effect (Fig. $1 B$ ). Note that IL-8 used as a positive control stimulated PMN migration at about the concentration present in conditioned medium from hypoxic ECs. The increase in IL-8 production was observed only when the $\mathrm{PO}_{2}$ was low (14-18 Torr) and was not seen at higher oxygen tensions. Release of IL-8 into the conditioned medium was not a result of cell death (even at the longest times of exposure to hypoxia, $16 \mathrm{~h}$ in these experiments), as cell viability was unaffected: cells remained adherent as a confluent monolayer, excluded trypan blue, and did not release increased amounts of lactate dehydrogenase.

As a first step in extrapolating these data back to an intact vessel, elaboration of IL-8 antigen in human umbilical cord segments, in which pieces of umbilical vein were exposed to hypoxia, were studied. In these experiments, the hypoxic segments demonstrated increased amounts of IL-8 antigen compared with normoxic controls (Fig. 2). Although multiple cells in the vessel wall could contribute to the observed IL-8 production, taken together with the data in cell culture, these results are consistent with increased elaboration of IL- 8 by hypoxic vasculature.

In parallel with increased levels of IL-8 in conditioned media from hypoxic cultured ECs, PCR analysis showed enhanced levels of IL-8 mRNA (Fig. $3 \mathrm{~A}$ ). Southern blotting of the PCR products with a CDNA for IL-8 confirmed the identity of these amplicons (Fig. $3 \mathrm{~B}$ ). Amplification of the same cDNA for GAPDH demonstrated that levels of transcript for this constitutive enzyme were unaffected by hypoxia, confirming preferential induction of IL-8 mRNA (Fig. $3 C$ ). Nuclear run-on assays demonstrated that hypoxia increased transcription of IL-8, whereas transcription of the housekeeping gene $\beta$-actin was largely unchanged (Fig. $3 D$ ). Since total transcription was decreased in hypoxia by $67 \%$ (data not shown), this suggests the specificity of the hypoxic stimulus for induction of IL-8. These data are consistent with increased IL-8 synthesis in hypoxia, resulting from enhanced transcription, translation, and release of chemotactically active protein. In support of upregulation of genes in the chemokine superfamily of cytokines, increased transcripts of MCP-1 were observed on Northern analysis of RNA from hypoxic ECs compared with normoxic controls (Fig. 4). Enhanced levels of MCP-1 mRNA were evident 30-60 min after placement in hypoxia and were increased up to $2 \mathrm{~h}$, thereafter falling off to the normoxic baseline by $4 \mathrm{~h}$.

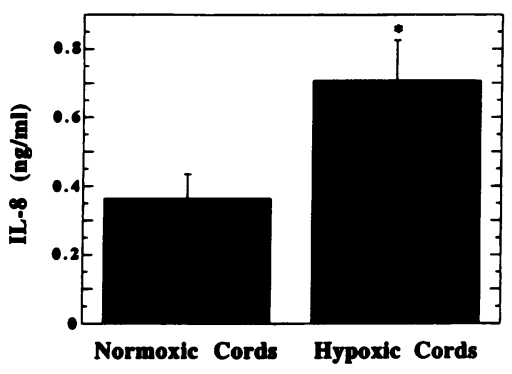

Figure 2. Elaboration of IL-8 antigen by umbilical vein segments exposed to hypoxia. Umbilical cord segments from patients were prepared and exposed to hypoxia for $6 \mathrm{~h}$ as described in the text. Aliquots of conditioned medium were analyzed using the IL-8 ELISA.

The mean \pm SEM of triplicate determinations is shown. ${ }^{*} P<0.05$, hypoxia vs normoxia.
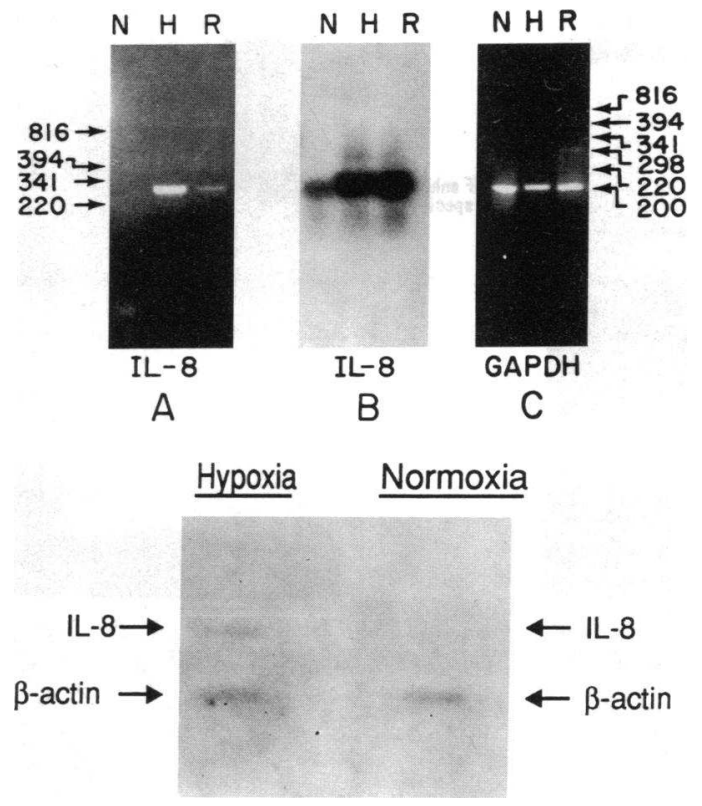

Figure 3. Induction of IL-8 mRNA in hypoxic ECs. ( $A$ and $C$ ) PCR analysis. ECs were placed either in normoxia $(N)$ hypoxia $(16 \mathrm{~h} ; H)$ or hypoxia $(16 \mathrm{~h}) /$ reoxygenation $(4 \mathrm{~h})(H / R)$, RNA was harvested, and PCR was performed as described in the text. First-strand CDNA was prepared from total RNA $(1 \mu \mathrm{g})$ and served as a template for PCR in combination with primers specific for IL-8 $(A)$ and GAPDH $(C)$. Results shown are ethidium bromide-stained PCR products obtained after 30 cycles. $C$ shows Southern hybridization of the PCR products obtained in $A$ using ${ }^{32} \mathrm{P}$-labeled cDNA for human IL-8. The migration of DNA markers (PhiX174 RF DNA-Hae III digest) is indicated by the arrows. $(D)$ Transcriptional analysis of IL-8 and $\beta$ actin genes by nuclear run-on assay. $4 \mu \mathrm{g}$ of IL-8 plasmid (top) and $\beta$-actin plasmid (bottom) bound to nitrocellulose were hybridized with ${ }^{32}$ P-labeled run-on transcripts from $7.2 \times 10^{6}$ nuclei isolated from cultured ECs after hypoxia $(3 \mathrm{~h})$ or normoxia.

Mechanisms of hypoxia-induced IL-8 production. Reactive oxygen intermediates, whose formation is often related to changes in intracellular redox potential, have been shown to induce nuclear translocation of the transcription factor NF-kB (43). Since a sequence element resembling an NF-kB recognition motif is present in the human IL-8 promoter, electrophoretic mobility shift assays were performed using a synthetic, double-stranded DNA probe representing this portion of the IL-8 promoter (Fig. 5). Addition of nuclear extract from nor-

MCP-1

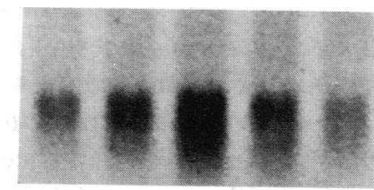

GAPDH
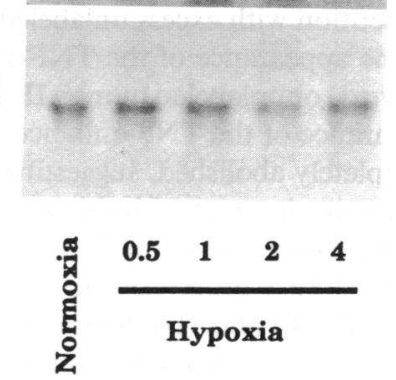

Figure 4. Northern analysis of hypoxic EC RNA for MCP-1. ECs were subjected to hypoxia for the indicated times or normoxia. Total RNA was extracted and subjected to Northern analysis with radiolabeled probe for MCP$1.8 \mu \mathrm{g}$ of RNA was added to each lane. Expression of GAPDH is used as an internal control. 

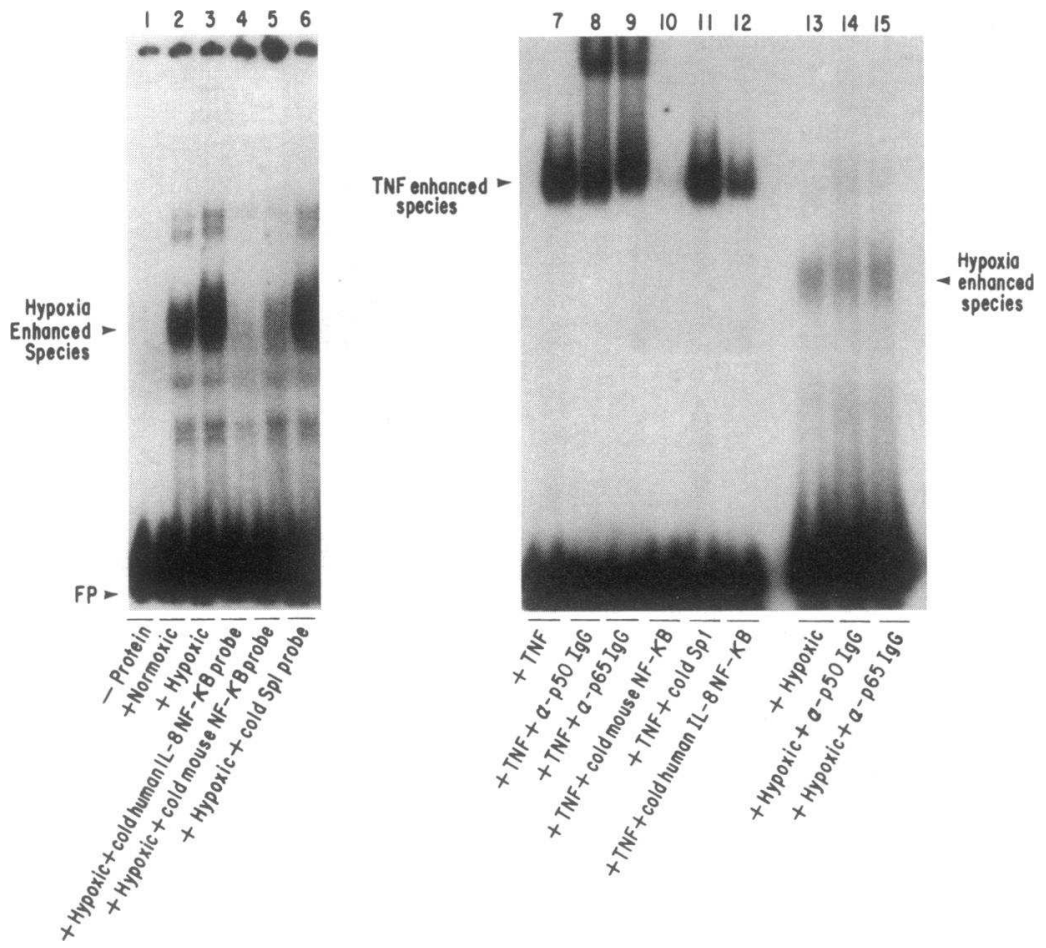

Figure 5. Binding of EC nuclear proteins to the human IL-8 promoter sequence: electrophoretic mobility shift assay. The binding of multiple nuclear proteins to the putative NF-kB site of the human IL-8 promoter and a known mouse NF-kB site was demonstrated using electrophoretic mobility shift assay. Lanes 1-6 and 13-15 contain the labeled probe representing the human IL-8 promoter, lanes $7-12$ contain the mouse probe. $F P$, unbound free probe. Additions are indicated above each lane, and details of methods are described in the text. moxic ECs resulted in the appearance of multiple shifted bands (compare lanes 1 and 2). Exposure of ECs to hypoxic conditions for $3 \mathrm{~h}$ resulted in a substantial increase in the binding capacity of one of these species (see lane 3 ), indicated as the hypoxia-enhanced species. The binding of this protein(s) to the probe is sequence specific, since an excess of the unlabeled human IL-8 promoter probe (lane 4) or of a probe containing a known murine NF-kB binding site (lane 5 ) virtually abolished binding to the labeled probe, whereas a similar molar excess of an unrelated probe containing a known Sp-1 binding site did not (lane 6).

The fact that both probes which contain known or putative NF-kB binding sites compete for binding of the hypoxia-induced species strongly suggests that this protein $(\mathrm{s})$ recognizes an NF-kB site. Since NF-kB is one member of a family of transcription factors that bind to similar recognition sequences (36-37), we sought to determine whether the hypoxia-induced species is authentic NF-kB (i.e., the p50/p65 heterodimer) or a distinct species. Since TNF is a known inducer of NF-kB in ECs (44), normoxic cultures were exposed to TNF and tested for binding activities that could specifically recognize the known NF-kB probe (Fig. 5, lanes 7-9). A major binding species, designated TNF-enhanced species (lanes 7-12) is observed in nuclear extracts from TNF-treated ECs. The sequence specificity of DNA binding by these protein(s) for a probe comprised of a known murine NF-kB sequence (33-34) is demonstrated by competition with excess unlabeled murine NF-kB probe (lane 10; the appearance of the TNF-enhanced band is completely abolished) or unlabeled human IL-8 NF-kB probe (lane 12; the appearance of the TNF-enhanced band is diminished, but not completely abolished, suggesting that the TNF-induced binding proteins interact with this probe with a lower affinity than with the mouse NF-kB probe). In contrast, addition of excess unlabeled Sp-1 probe had no effect on the intensity of the TNF-enhanced band. To determine that the TNF-induced species binding to NF-kB was authentic NF-kB, supershift experiments were performed with antisera to the p50 and p65 components of NF-kB. The results demonstrate that the TNF enhanced species is shifted by both the anti-p50 (lane 8 ) and anti-p65 antisera (lane 9 ). In conjunction with the competition data, these data are strong evidence that the species induced/enhanced by TNF is authentic NF-kB. In contrast, supershift experiments with the same antibodies did not result in a shift of the hypoxia-enhanced species (lane 14, anti-p50 IgG; lane 15, anti-p65 IgG). The different mobility of the hypoxia-enhanced species relative to NF-kB in the gel mobility shift assay suggests that although it binds to NF-kB binding sites, it is distinct from authentic NF-kB.

Effect of hypoxia on leukostasis and induction of murine members of the IL-8-related family of chemokines in the mouse. Mice exposed to hypoxia demonstrated increased pulmonary leukostasis, as measured by MPO assays (Fig. $6 \mathrm{~A}$ ). These results led us to examine if hypoxia was a stimulus for induction of cytokines in the IL-8-related murine family of chemoattractant polypeptides in vivo. A fragment corresponding to the expected 475-bp PCR product from IP-10 mRNA was observed at 4 and $8 \mathrm{~h}$ after exposure to hypoxia and declined after $24 \mathrm{~h}$ (Fig. $6 \mathrm{~B}$ ). IP-10 mRNA was not detected in normoxic control animals. Southern blotting with IP- $10 \mathrm{cDNA}$ confirmed the identity of the amplicon (Fig. $6 C$ ). In contrast, no induction of gro $(\mathrm{KC}) \mathrm{mRNA}$ was observed.

\section{Discussion}

Exposure of ECs to hypoxia and hypoxia/reoxygenation sets in motion events that promote margination and migration of PMNs into the interstitium. Previous studies have demonstrated mechanisms through which ECs subjected to hypoxia, as well as reoxygenation have increased capacity to bind PMNs $(18,45)$. EC generation of a chemotactic polypeptide in ischemic loci could enhance the participation of circulating PMNs in the inflammatory response. In this report, we show that hyp- 

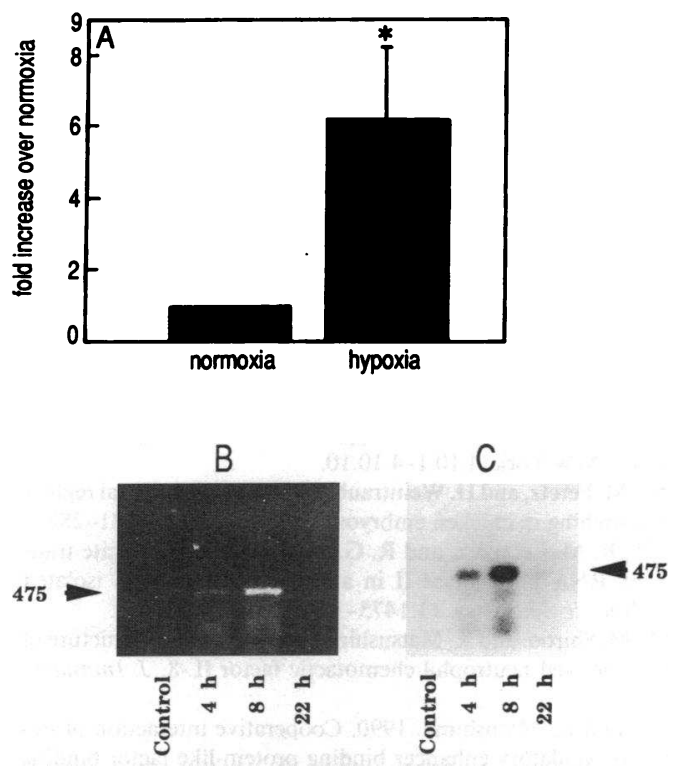

Figure 6. Effect of hypoxia on pulmonary leukostasis and activation of genes in the IL-8-related family in vivo. Mice were exposed to hypoxia $\left(\mathrm{PO}_{2} \sim 30-40\right.$ Torr, $n=3$ ) or normoxia (ambient $\mathrm{PO}_{2}$, $n=3$ ). (A) Lungs were harvested at $16 \mathrm{~h}$ and processed for MPO activity. The y-axis shows the fold increase in MPO activity in hypoxic mouse lung as compared with normoxic controls (mean $\pm \mathrm{SEM}$ ). ${ }^{*} P$ $<0.05$. (B) Lungs were harvested at 4,8 , and 22 h of hypoxia, RNA was extracted, and PCR was performed using primers for IP-10. The arrow indicates the position of the expected 475-bp PCR product. $(C)$ Southern hybridization of these amplicons with a radiolabeled IP-10 cDNA.

oxia results in the production of the chemotactic cytokine IL-8, providing insight into a means through which ECs facilitate emigration of PMNs from the intravascular space, either by releasing IL-8 or, potentially, displaying this polypeptide on the cell surface (46-47). After their adherence to the EC, PMNs emigrate to the extravascular tissues, where they fulfill their role in host defense.

Although pathways underlying enhanced EC expression of IL-8 in hypoxia remain to be clarified, the association of this phenomenon with activation of an NF-kB-related transcription factor may be an important mechanism driving transcription. Consistent with the presence of NF-kB and C/EBP binding sites in the promoter of the human IL-8 gene, NF-kB, along with a C/EBP-like factor, can drive expression of IL-8 (35). The different mobility of the hypoxia-induced NF-kB species, compared with that observed in EC cultures exposed to TNF, as well as the supershift experiments with anti-p50 and antip65 antibodies, indicates that a species distinct from authentic NF-kB may be involved in transcriptional activation in hypoxic cultures. In view of the evolving recognition of the diverse and complex nature of the NF-kB-related family of molecules (36-37), it is not surprising that different stimuli might use distinct pathways to initiate transcription of target genes.

The stimulus for activation of NF-kB site binding activity in hypoxic ECs could result from several possible mechanisms. For example, hypoxia-induced production of EC IL-1 could result in autocrine activation of NF-kB site binding activity. The latter seems unlikely, as induction of IL-1 mRNA and elaboration of IL-1 activity from hypoxic ECs occurs later than activation of NF-kB binding site activity and induction of IL-8 (18). In support of this, anti-IL-1 antibodies and IL-1 receptor antagonist had no effect on hypoxia-induced IL-8 production. Studies are in progress to delineate mechanisms which are involved.

Our data in the mouse model of hypoxia, also suggest potential hypoxia-induced activation of other members of the IL-8-related family of proinflammatory polypeptides. Induction of IP-10 is associated with inflammation, for example its production is stimulated by $T$ cell-derived lymphokines (IFN$\gamma$, IL-2, TNF) and bacterial cell wall lipopolysaccharide, although the biologic activities of IP-10 have not been fully defined (22). To gain further insight into possible upregulation of the murine IL-8 gene in hypoxia, we obtained a recently cloned cDNA which appears to be the murine counterpart of IL-8 (30\% identical and 50\% homologous to human IL-8) (Weinstein, I.B., and W. Jing, manuscript in preparation), and performed Northern analysis on RNA harvested from hypoxic mouse lung tissue. The intensity of a band corresponding to the IL-8 mRNA increased in hypoxia at the 1-, 2-, and 4-h time points, compared with normoxic controls. These observations are consistent with the leukostasis observed with hypoxia in vivo, and the results with cultured ECs and with umbilical cord segments demonstrating increased elaboration of IL-8 antigen on exposure to hypoxia.

Taken together, these data indicate that hypoxia enhances EC transcription, translation, and release of the IL-8 gene product, potentially attracting PMNs to areas of regional ischemia. The combined effects of EC production of IL-8 during hypoxia, and monocyte elaboration of IL-8 during reoxygenation (8) could lead to a synergistic mechanism through which leukocytes are drawn into the interstitium. Thus, regional hypoxia/hypoxemia could serve as a priming stimulus that initiates a local inflammatory response after reoxygenation/reperfusion.

\section{Acknowledgments}

Drs. Gabriel Godman and Peter Caldwell provided advice during the course of these studies and suggestions during preparation of the manuscript.

This work was supported by grants from the Public Health Service (HL-08284, HL-34625, HL-42507, HL-42883, HL-21006, HL29589), the Council for Tobacco Research (CTR2101R1), the StonyWold Foundation, and the New York Heart Association. D. Stern completed this work during the tenure of a Genentech-EI Award from the American Heart Association.

\section{References}

1. Sibille, Y., and H. Y. Reynolds. 1990. Macrophages and polymorphonuclear leukocytes in lung defense and injury. Am. Rev. Respir. Dis. 141:471-501.

2. Rot, A. 1991. Some aspects of NAP-1 pathophysiology: lung damage caused by a blood borne cytokine. In Chemotactic Cytokines. Plenum Publishing Corporation, New York. pp. 127-135.

3. von Euler, U., and G. Liljestrand. 1946. Observations on the pulmonary arterial blood pressure in the cat. Acta Physiol. Scand. 12:301-306.

4. Dreyer, W. J., L. H. Michael, M. S. West, C. W. Smith, R. Rothlein, R. D. Rosen, D. C. Anderson, and M. L. Entman. 1988. Neutrophil accumulation in ischemic canine myocardium. Circulation. 84:400-411.

5. Granger, D. 1988. Role of xanthine oxidase and granulocytes in ischemiareperfusion injury. Am. J. Physiol. 255:H1269-1275.

6. Mullane, K., and C. Smith. 1990. The role of leukocytes in ischemic damage, reperfusion injury and repair in the myocardium. In Pathophysiology of Severe Ischemic Myocardial Injury. Kluwer Academic Publishers, Dordrecht, The Netherlands. pp. 239-267. 
7. Crawford, M., F. Grover, W. Kolb, C. McMahan, R. O'Rourke, L. McManus, and R. Pinckard. 1988. Complement and neutrophil activation in the pathogenesis of ischemic myocardial injury. Circulation. 78:1449-1458.

8. Mullane, K., N. Read, J. Salmon, and S. Moncada. 1984. Role of leukocytes in acute myocardial infarction in anesthetized dogs. J. Pharmacol. Exp. Ther. 228:510-522.

9. Lucchesi, B., and K. Mullane. 1986. Leukocytes and ischemia induced myocardial injury. Annu. Rev. Pharmacol. Toxicol. 26:201-224.

10. Schmid-Schoenbein, G., and R. Engler. 1987. Granulocytes as active participants in acute myocardial ischemia and infarction. Am. J. Cardiovasc. Pathol. 1:15-30.

11. Zweier, J., P. Kuppusamy, and G. Lutty. 1988. Measurement of endothelial cell free radical generation: evidence for a central mechanism of free radical injury in postischemic tissues. Proc. Natl. Acad. Sci. USA. 85:4046-4050.

12. Ratych, R., R. Chuknyiska, and G. Bulkley. 1987. The primary localization of radical generation after anoxia/reoxygenation in isolated endothelial cells. Surgery (St. Louis). 102:122-131.

13. Shlafter, M., K. Brosamer, J. Forder, R. Simon, P. Ward, and C. Grum. 1990. Cerium chloride as a histochemical marker of hydrogen peroxide in reperfused ischemic hearts. J. Mol. Cell Cardiol. 22:83-97.

14. Babbs, C., M. Cregor, J. Turek, and S. Badylak. 1991. Endothelial superoxide production in the isolated rat heart during reperfusion after ischemia. Am. J. Path. 139:1069-1080.

15. Kubes, P., G. Ibbotson, J. M. Russel, J. L. Wallace, and D. N. Granger. 1990. Role of platelet-activating factor in ischemia-reperfusion induced leukocyte adherence. Am. J. Physiol. 259:G300-305.

16. Filep, J., F. Herman, P. Braquet, and T. Mozes. 1989. Increased levels of platelet-activating factor in blood following intestinal ischemia in the dog. Biochem. Biophys. Res. Comm. 158:353-359.

17. Montrucchio, G., G. Alloatti, F. Mariano, R. dePaulis, A. Comino, G. Emanuelli, and G. Camussi. 1990. Role of platelet-activating factor in the reperfusion injury of rabbit ischemic heart. Am. J. Pathol. 137:71-83.

18. Shreeniwas, R., S. Koga, M. Karakurum, D. Pinsky, E. Kaiser, J. Brett, B. A. Wolitzky, C. Norton, J. Plocinski, W. Benjamin, et al. 1992. Hypoxia mediated induction of endothelial cell interleukin $1 \alpha$ : an autocrine mechanism promoting expression of leukocyte adhesion molecules on the vessel surface. J. Clin. Invest. 90:2333-2339.

19. Koga, S., S. Ogawa, K. Kuwabara, J. Brett, J. Leavy, J. Ryan, Y. Koga, J. Plocinski, W. Benjamin, D. Burns, and D. Stern. 1992. Synthesis and release of IL-1 by reoxygenated human mononuclear phagocytes. J. Clin. Invest. 90:10071015.

20. Baggiolini, M., A. Waltz, and S. Kunkel. 1989. Neutrophil-activating peptide-1/interleukin-8, a novel cytokine that activates neutrophils. J. Clin. In vest. 84:1045-1049.

21. Peveri, P., A. Walz, B. DeWald, and M. Baggiolini. 1988. A novel neutrophil-activating factor produced by human mononuclear phagocytes. $J$. Exp. Med. 167:1547-1559.

22. Oppenheim, J. J., C. O. C. Zachariae, N. Mukaida, and K. Matsushima. 1991. Properties of the novel proinflammatory supergene "intercrine" cytokine family. Annu. Rev. Immunol. 9:617-648.

23. Metinko, A. P., S. L. Kunkel, T. J. Sandiford, and R. M. Streiter. 1992 Anoxia-hyperoxia induces monocyte driven IL-8. J. Clin. Invest. 90:791-798.

24. Jaffe, E. A., R. L. Nachman, C. G. Becker, and R. C. Minick. 1973. Culture of human endothelial cells derived from umbilical veins. Identification by morphologic and immunologic criteria. J. Clin. Invest. 52:2745-2756.

25. Thornton, S. C., S. N. Mueller, and E. M. Levine. 1983. Human endothelial cells: use of heparin in long-term cloning and serial cultivation. Science (Wash. DC). 222:623-625.

26. Ogawa, S., H. Gerlach, C. Esposito, A. Pasagian-Macaulay, J. Brett, and D. Stern. 1990. Hypoxia modulates barrier and coagulant function of cultured bovine endothelium: increased monolayer permeability and cell surface coagulant properties. J. Clin. Invest. 85:1090-1098.

27. Sandiford, T. J., S. L. Kunkel, M. A. Basha, S. W. Chensue, J. P. Lynch, G. B. Toews, J. Westwick, and R. M. Strieter. 1990. Interleukin-8 gene expression by a pulmonary epithelial cell line: a model for cytokine networks in the lung. $J$. Clin. Invest. 86:1945-1953.

28. Boyden, S. 1962. The chemotactic effects of mixtures of antibody and antigen on polymorphonuclear leukocytes. J. Exp. Med. 115:453-456.

29. Boyum, A. 1968. Isolation of mononuclear leukocytes and granulocytes from human blood. Scand. J. Lab. Invest. 21 (Suppl. 97):77-81.

30. Carre, P. C., R. L. Mortenson, T. E. King, Jr., P. W. Noble, C. L. Sable, and D. W. H. Riches. 1991. Increased expression of interleukin-8 gene by alveolar macrophages in idiopathic pulmonary fibrosis. J. Clin. Invest. 88:1802-1810.

31. Greenberg, M., and T. Bender. 1988. Identification of newly transcribed RNA. In Current Protocols in Molecular Biology, Greene Publishing Associates and Wiley Interscience, New York. 4.10.1-4.10.10.

32. Groudine, M., M. Peretz, and H. Weintraub. 1981. Transcriptional regulation of hemoglobin switching in chicken embryos. Mol. Cell. Biol. 1:281-288.

33. Dignam, J. P., R. M. Lebovitz, and R. G. Roeder. 1983. Accurate transcription initiation by RNA polymerase II in a soluble extract from isolated mammalian nuclei. Nucleic Acids Res. 11:1475-1489.

34. Naofumi, M., M. Shiroo, and K. Matsushima. 1989. Genomic structure of the human monocyte-derived neutrophil chemotactic factor IL-8. J. Immunol. 143:1366-1371.

35. Mukaida, N., and K. Matushima. 1990. Cooperative interaction of nuclear factor-kB and cis-regulatory enhancer binding protein-like factor binding elements in activating the interleukin 8 gene by proinflammatory cytokines. $J$. Biol. Chem. 265:21128-21133.

36. Sen, R., and D. Baltimore. 1986. Multiple nuclear factors interact with the immunoglobulin enhancer sequences. Cell. 46:705-716.

37. Baeuerle, P. 1991. The inducible transcription factor NF-kB: regulation by distinct protein subunits.

38. Maniatis, T., E. Fritsch, and J. Sambrook. 1992. Molecular Cloning. Cold Spring Harbor Laboratory, Cold Spring Harbor, New York.

39. Rice, N., M. MacKichan, and A. Israel. 1992. The precursor of NF-kB has IkB-like functions. Cell. 71:243-253.

40. Anderson, M., and S. Freytag. 1991. Synergistic activation of a human promoter in vivo by transcription factor Sp1. Mol. Cell. Biol. 11:1935-1943.

41. Goldblum, S. E., K. M. Wu, and M. Jay. 1985. Lung myeloperoxidase as a measure of pulmonary leukostasis in rabbits. J. Appl. Physiol. 59:1978-1985.

42. Lo, S. K., J. Everitt, J. Gu, and A. B. Malik. 1992. Tumor necrosis factor mediates experimental pulmonary edema by ICAM-1 and CD18-dependent mechanisms. J. Clin. Invest. 89:981-988.

43. Schreck, R., P. Rieber, and P. A. Bauerle. 1991. Reactive oxygen intermediates as apparently widely used messengers in the activation of the NF-kB transcription factor and HIV-1. EMBO (Eur. Mol. Biol. Organ.) J. 10:2247-2258.

44. Montgomery, K., L. Osborn, C. Hession, R. Tizard, D. Goff, C. Vassalo, P. Tarr, K. Bomsztyk, R. Lobb, and J. Harlan. 1991. Activation of endothelialleukocyte adhesion molecule-1 gene transcription. Proc. Natl. Acad. Sci. USA. 88:6523-6527.

45. Yoshida, N., D. Granger, D. Anderson, R. Rothlein, C. Lane, and P. Kvietys. 1992. Anoxia/reoxygenation induce neutrophil adherence to cultured endothelial cells. Am. J. Physiol. 262:H1891-1898.

46. Rot, A. 1992. Endothelial cell binding NAP-1/IL-8: role in neutrophil emigration. Immunol. Today. 13:29 i-294.

47. Detmers, P. A., S. K. Lo, E. Olsen-Egbert, A. Walz, M. Baggiolini, and Z. A. Cohn. 1990. Neutrophil activating protein 1-interleukin-8 stimulates binding activity of the leukocyte adhesion receptor CD11b/CD18 on human neutrophils. J. Exp. Med. 171:1155-1162. 